\title{
Создание ПЦР-тест-системы для выявления некоторых видов азотфиксирующих бактерий
}

\author{
Черкасов М. ${ }^{1 *}$, Байкалов М. ${ }^{1}$, Андамова В. ${ }^{1}$, Парамоник А.Н. ${ }^{2}$, Воронина Е.Н. ${ }^{1,2}$ \\ ${ }^{1}$ Специализированный учебно-научный центр Новосибирского государственного университета, \\ Новосибирск, Россия \\ ${ }^{2}$ Региональный центр выявления и поддержки одаренных детей «Альтаир», Новосибирск, Россия \\ *m.cherkasov@school.nsu.ru
}

Ключевые слова: азотофиксирующие бактерии, праймеры, определение вида

Мотивация $u$ цеель: К настоящему времени установлено, что многие свободноживущие бактерии - представители около 30 видов - могут фиксировать молекулярный азот. Большое значение в фиксации азота имеет семейство Azotobacteriaceae, однако, как показали последние исследования, в почве могут находиться азотфиксирующие бактерии рода Klebsiella и рода Enterobacter (семейство Enterobacteriaceae) и др. Важно быстро и эффективно определять виды азотфиксирующих бактерий для изучения их распространения и поиска новых видов, которые могут быть полезны для совершенствования технологий улучшения урожайности и восстановления почв. Нашей целью было подобрать праймеры, специфичные к виду Azotobacter chroococcum, виду Azotobacter vinelandii, роду Enterobacter.

Meтоды и алгоритмы: Для подбора праймеров мы использовали базу данных NCBI BLAST и программу UGENE. Для апробации и дальнейшей визуализации полученных результатов использовали метод ПЦР и гель-электрофореза. Проводили оптимизацию по температуре отжига.

Pезультаты: Праймеры на Azotobacter chroococcum сработали неспецифично амплификация проходила на представителях разных родов, хотя и получался фрагмент разной длины. Праймеры на Azotobacter vinelandii сработали специфично, т. е. ПЦР проходила только на ДНК, выделенной из Azotobacter vinelandii. Праймеры для Enterobacter работали на всех представителях как семейства Azotobacteriaceae, так и семейства Enterobacteriaceae.

Заключение: Из трех праймеров корректно сработали только праймеры на Azotobacter vinelandii, в других случаях требуются доработка или использование других методов, например рестрикционного анализа. 